\title{
Immunohistochemical Demonstration of EMA/Glut1- Positive Perineurial Cells and CD34-Positive Fibroblastic Cells in Peripheral Nerve Sheath Tumors
}

Takanori Hirose, M.D., Takayuki Tani, M.D., Tetsuya Shimada, M.D., Keisuke Ishizawa, M.D., Shio Shimada, M.D., Toshiaki Sano, M.D.

Department of Pathology (TH, TT, TS, KI, SS), Saitama Medical School, Saitama; and Department of Pathology (TS), University of Tokushima School of Medicine, Tokushima, Japan

To clarify the cellular composition of various peripheral nerve tumorous lesions (traumatic neuroma, 5 cases; schwannoma, 10 cases; neurofibroma, 14 cases; perineurioma, 3 cases; conventional malignant peripheral nerve sheath tumor (MPNST), 7 cases; perineurial MPNST, 4 cases), expression of several markers specific to nerve sheath cells, including glucose transporter protein 1 (Glut1) and CD34, were immunohistochemically investigated with highly sensitive detection methods. In normal nerves and neuromas, perineuriums were positive for Glutl as well as for epithelial membrane antigen (EMA), and there were some CD34-positive fibroblast-like cells in the endoneurium. Schwannomas consisted principally of S-100 protein-positive Schwann cells, whereas a few CD34-positive fibroblastic cells were present in Antoni $B$ areas. Neurofibromas and conventional MPNST exhibited a mixed proliferation of S-100 protein-, EMA/ Glut1-, and CD34-positive cells, indicating a heterogeneous composition of the constituents. The catalyzed signal amplification (CSA) system demonstrated more numerous EMA-positive perineurial cells in neurofibromas than did the ENVISION+ method. Perineurial cell tumors (benign and malignant) were composed of EMA/Glut1-positive and S-100 protein-negative tumor cells. The present study confirmed the characteristic cellular composition to each nerve sheath tumor immunohistochemically and showed the usefulness of the nerve sheath cell markers. Glutl as well as EMA are specific to perineurial cells, and $\mathrm{CD34}$ seems to be immunoreactive to endoneurial fibroblasts.

Copyright $(\odot 2003$ by The United States and Canadian Academy of Pathology, Inc.

VOL. 16, NO. 4, P. 293, 2003 Printed in the U.S.A.

Date of acceptance: January 9, 2003.

Address reprint requests to: Takanori Hirose, M.D., Department of Pathology, Saitama Medical School, Moroyama, Saitama, Japan, 350-0495; fax: 81-49-276-1583; e-mail: thirose@saitama-med.ac.jp.

DOI: 10.1097/01.MP.0000062654.83617.B7
KEY WORDS: CD34, EMA, Endoneurial fibroblast, Glut1, Immunohistochemistry, Perineurial cell, Peripheral nerve sheath tumor.

Mod Pathol 2003;16(4):293-298

Nerve sheath cells of the peripheral nerve consist of Schwann cells, perineurial cells, and endoneurial fibroblasts (1). These cells exhibit characteristic ultrastructural features and immunophenotypes (1, 2). S-100 protein and epithelial membrane antigen (EMA) are known as specific markers to Schwann cells and perineurial cells, respectively (1-3). Recently, erythrocyte glucose transporter protein 1 (Glut1) was also reported to be expressed in perineurial cells (4). However, no specific markers have been identified to endoneurial fibroblasts.

Peripheral nerve sheath tumors and tumorlike lesions are composed of a proliferation of these nerve sheath cells in varied composition and proportion. Ultrastructural studies suggested that schwannomas are principally composed of Schwann cells (5). This is supported by a diffuse immunoreactivity of S-100 protein in schwannomas (6). Perineuriomas are composed of EMApositive cells, which also possess ultrastructural characteristics of perineurial cells (7). On the other hand, although ultrastructural studies have demonstrated the presence of Schwann cells, perineurial cells, and fibroblastic cells $(5,8)$, the participation of perineurial cells in neurofibromas has not fully been proven immunohistochemically (9). The constituents of malignant peripheral nerve sheath tumors (MPNST) are still poorly understood. Furthermore, CD34-positive cells are frequently observed in nerve sheath lesions, but the nature of the positive cells remains to be clarified (10).

To clarify these issues, we studied the expression of immunohistochemical markers specific to nerve sheath cells in various nerve sheath lesions. Because EMA usually exhibits weak immunoreactivity 
to normal perineurial cells, a highly sensitive detection method was also used.

\section{MATERIALS AND METHODS}

Nerve sheath lesions studied included traumatic neuroma (5 cases), schwannoma (10 cases), neurofibroma (14 cases), perineurioma (3 cases), conventional MPNST (7 cases), and MPNST with perineurial differentiation (4 cases). All neurofibromas except for one cutaneous plexiform type were localized neurofibromas (11). Four tumors of MPNST arose in patients with neurofibromatosis Type 1 and another in a neurofibroma. Perineurial cell features were ultrastructurally confirmed in all tumors of perineurioma and perineurial MPNST. Perineuriomas consisted of one sclerosing perineurioma (12) and two soft-tissue perineuriomas. Two cases of the perineurial MPNST have previously been reported (13).

Using the ENVISION + method (DAKO, Carpinteria, CA), the following antigens were detected in formalin-fixed, paraffin sections: S-100 protein (polyclonal, dilution 1:300; DAKO), EMA (monoclonal, clone E29, 1:100; DAKO), CD34 (monoclonal, clone My10, 1:30, pretreatment required in an autoclave for 5 minutes at $121^{\circ} \mathrm{C}$; Becton Dickinson, San Jose, CA), and Glutl (polyclonal, 1:200, pretreatment required in an autoclave for 5 minutes at $121^{\circ} \mathrm{C}$; DAKO). The ENVISION + method uses high molecular weight polymers labeled with many secondary antibodies and horseradish peroxidase to simply obtain a highly sensitive reactivity. Furthermore, the catalyzed signal amplification (CSA) system (DAKO) was used for the detection of EMA. The CSA system greatly increases the sensitivity of the immunoreactivity, using biotinylated tyramide (14).

\section{RESULTS}

Immunohistochemical results are summarized in Table 1.
In normal nerves, EMA was expressed only in perineuriums, and immunoreactivity was enhanced by the CSA system. Glutl expression was also observed in perineuriums as well as erythrocyte membranes (Fig. 1A). A few spindle-shaped and stellate cells within the endoneurium were positive for CD34, whereas Schwann cells and perineurial cells were negative (Fig. 1B). Some mesenchymal cells outside the nerves as well as endothelial cells also exhibited CD34 immunoreactivity.

Small nerve fascicles proliferating in neuromas were surrounded by EMA- and Glut1-positive perineuriums (Fig. 2A). CD34 immunostains showed many positive cells, which were often localized between nerve fibers and the perineurium and were different from either S-100 protein-positive Schwann cells or EMA/Glut1-positive perineurial cells.

All schwannomas showed typical Antoni A and B patterns and nuclear palisading, often associated with ancient changes. Most tumor cells were diffusely positive for S-100 protein. The capsules were immunoreactive with EMA and Glutl (Fig. 3A). There were a few long, slender cells exhibiting both Glut1 and CD34 immunoreactivity in the peripheral areas close to the capsules (Fig. 4). Interestingly, some spindle- or stellate-shaped cells in myxoid Antoni B areas were immunoreactive to CD34, whereas $\mathrm{A}$ areas were devoid of positive cells (Fig. 3B).

In neurofibromas, many tumor cells with curved nuclei as well as Meissner-type tactoid bodies were positive for S-100 protein (Fig. 5A). All cases contained varied numbers of CD34-positive cells (Fig. 5B). CD34-positive cells were more numerous at the periphery of lesions and in fibrotic areas. In addition, multivacuolated cells floating in myxoid areas also showed CD34 positivity. EMA and Glut1 immunostains by ENVISION+ showed only a small number of positive cells, most of which were arranged in perineurium-like structures. However, the CSA system demonstrated more numerous

TABLE 1. Immunohistochemical Profiles of Peripheral Nerve Sheath Lesions

\begin{tabular}{|c|c|c|c|c|c|}
\hline Lesions $(\mathrm{N})$ & S-100 & EMA & EMA/CSA & Glut1 & CD34 \\
\hline Neuroma (2) & $\begin{array}{c}+++ \\
(100 \%)\end{array}$ & $\begin{array}{c}+ \\
(80 \%)\end{array}$ & $\begin{array}{c}++ \\
(100 \%)\end{array}$ & $\begin{array}{c}++ \\
(100 \%)\end{array}$ & $\begin{array}{c}++ \\
(100 \%)\end{array}$ \\
\hline Schwannoma (10) & $\begin{array}{c}+++ \\
(100 \%)\end{array}$ & $\begin{array}{c}+^{*} \\
(70 \%)\end{array}$ & $\begin{array}{c}+^{*} \\
(100 \%)\end{array}$ & $\begin{array}{c}+^{*} \\
(90 \%)\end{array}$ & $\begin{array}{c}+ \\
(100 \%)\end{array}$ \\
\hline Neurofibroma (14) & $\begin{array}{c}+++ \\
(100 \%)\end{array}$ & $\begin{array}{c}+ \\
(43 \%)\end{array}$ & $\begin{array}{c}+ \\
(100 \%)\end{array}$ & $\begin{array}{c}+ \\
(100 \%)\end{array}$ & $\begin{array}{c}++ \\
(100 \%)\end{array}$ \\
\hline Perineurioma (3) & $\begin{array}{c}- \\
(0 \%)\end{array}$ & $\begin{array}{c}+ \\
(33 \%)\end{array}$ & $\begin{array}{c}+ \\
(100 \%)\end{array}$ & $\begin{array}{c}+ \\
(67 \%)\end{array}$ & $\begin{array}{c}+ \\
(33 \%)\end{array}$ \\
\hline Conventional MPNST (7) & $\begin{array}{c}++ \\
(86 \%)\end{array}$ & $\begin{array}{c}- \\
(0 \%)\end{array}$ & $\begin{array}{c}+ \\
(86 \%)\end{array}$ & $\begin{array}{c}+ \\
(33 \%)\end{array}$ & $\begin{array}{c}+ \\
(57 \%)\end{array}$ \\
\hline Perineurial MPNST (4) & $\begin{array}{c}- \\
(0 \%)\end{array}$ & $\begin{array}{c}+ \\
(75 \%)\end{array}$ & $\begin{array}{c}++ \\
(100 \%)\end{array}$ & $\begin{array}{c}+ \\
(67 \%)\end{array}$ & $\begin{array}{c}+ \\
(25 \%)\end{array}$ \\
\hline
\end{tabular}

$\mathrm{N}=$ case number; EMA = epithelial membrane antigen; CSA = catalyzed signal amplification system; Glut1 = glucose transporter protein 1 ; MPNST = malignant peripheral nerve sheath tumor; $+++=$ many positive cells; $++=$ some positive cells; $+=$ a few positive cells; $-=$ negative; $(\%)$, percentage of positive cases; * = immunoreactivity in capsules. 


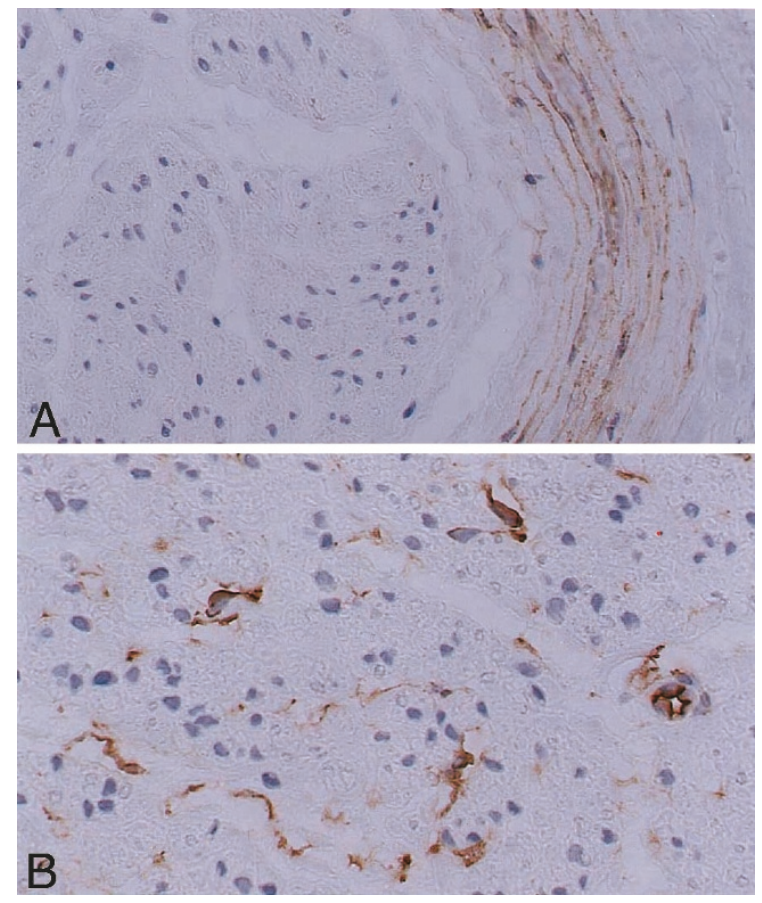

FIGURE 1. Normal nerve. A, perineurial cell layers showing immunoreactivity for Glut1. B, CD34-positive cells, spindle or stellate in shape, in the endoneurium.
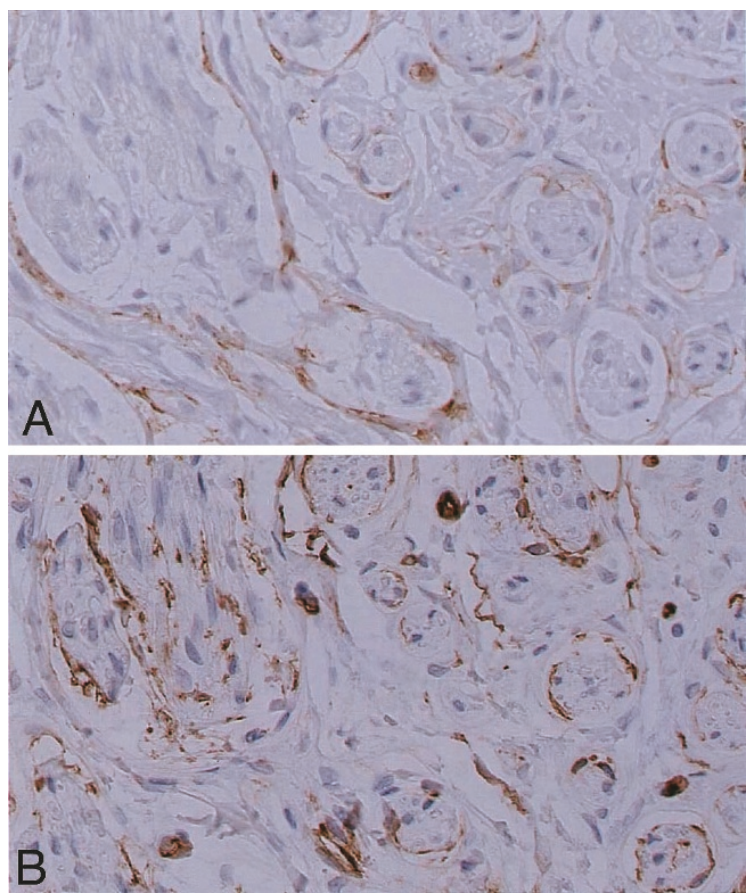

FIGURE 2. Neuroma. A, a proliferation of small nerve bundles surrounded by Glut1-positive perineurial cells. B, CD34-positive cells, distinct from Schwann cells or perineurial cells.

EMA-positive spindle cells that were scattered throughout the lesions (Fig. 5C).

Sclerosing perineurioma arising in the digit was composed of spindle and epithelioid cells in a densely fibrous background. The tumor cells were
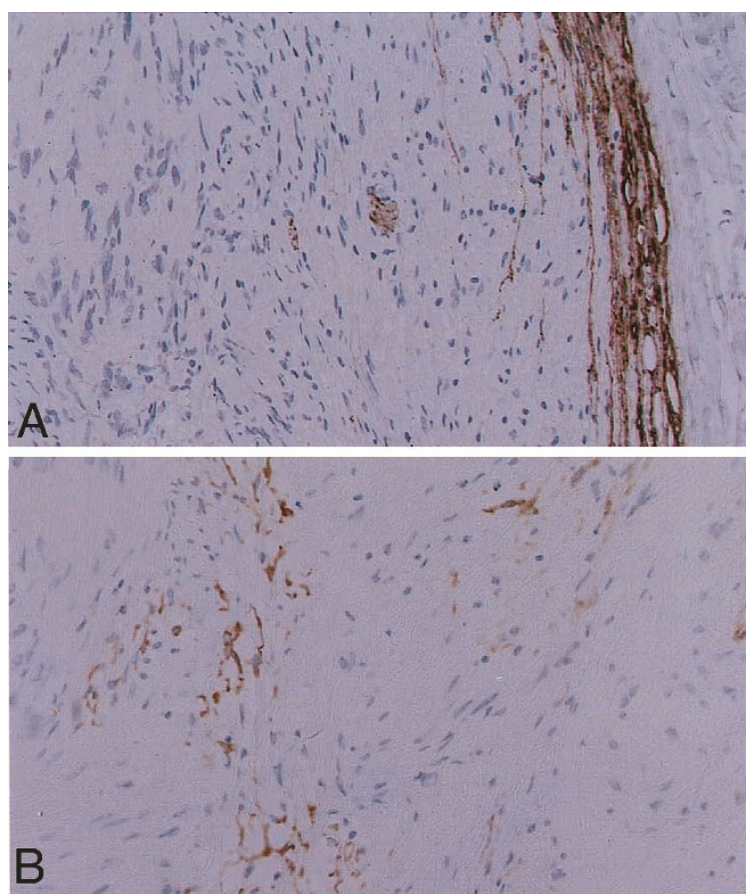

FIGURE 3. Schwannoma. A, Glut1-immunoreactivity restricted on the capsule. B, a few CD34-positive cells in Antoni B areas.
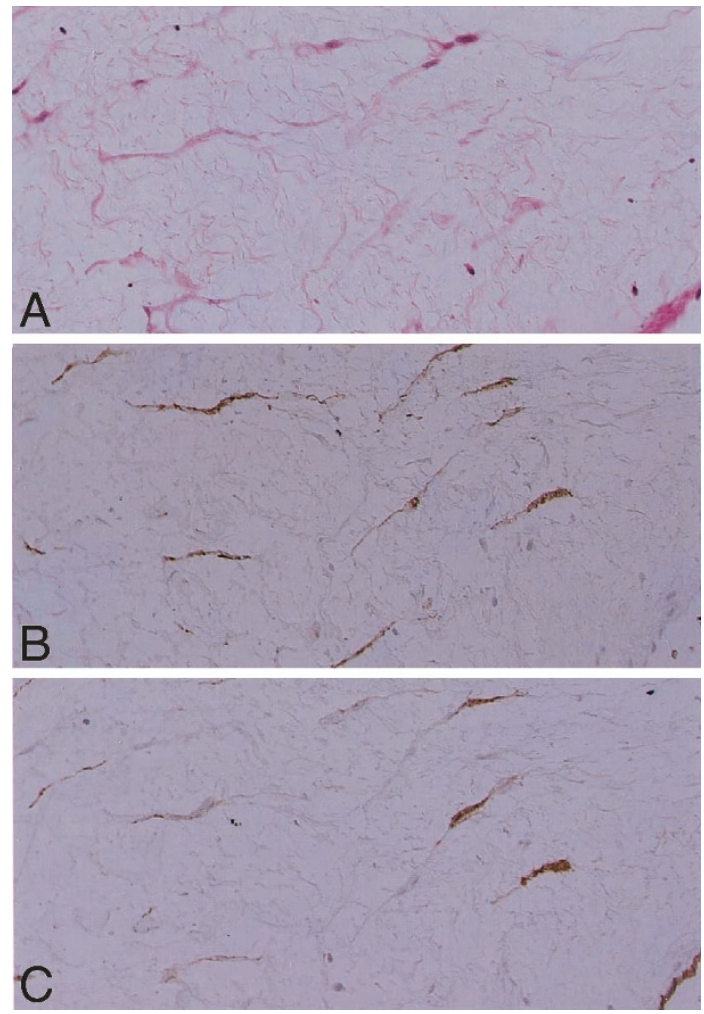

FIGURE 4. Schwannoma. Slender, spindle-shaped cells present close to the capsule (A), exhibiting both Glut1 (B) and CD34 (C) immunoreactivity.

S-100 protein negative but were positive for both EMA and Glutl (Fig. 6). In two cases of soft tissue perineurioma, spindle-shaped tumor cells exhib- 

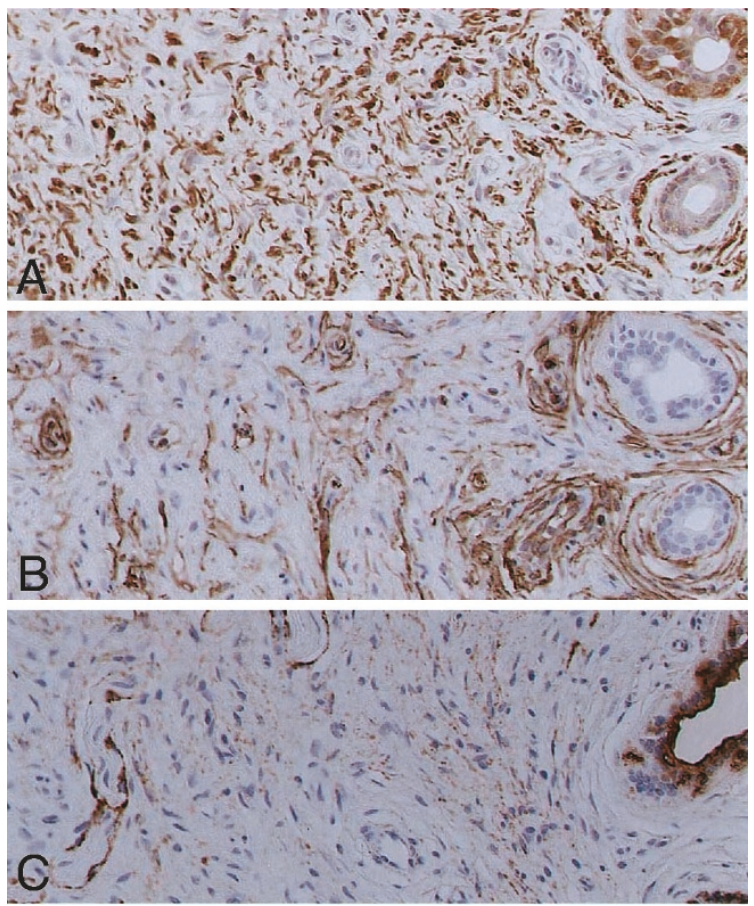

FIGURE 5. Neurofibroma. A, many S-100 protein-positive cells. B, several CD34-positive cells present in neurofibroma. C, EMA (CSA system) immunoreactivity on scattered spindle-shaped tumor cells, perineuriums of small nerve bundles, and epithelial cells of sweat glands.
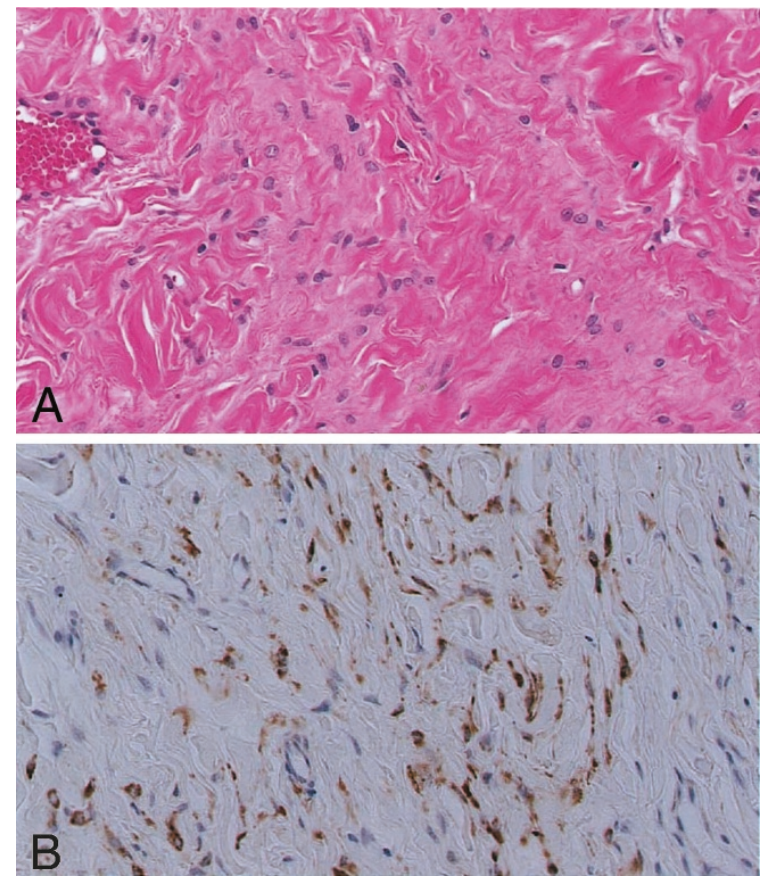

FIGURE 6. Sclerosing perineurioma. A, epithelioid or spindle-shaped tumor cells in fibrous stroma. B, EMA (CSA system)-positive cells arranged in a reticular pattern.

ited similar immunoreactivities: S-100 protein negativity and EMA positivity (by the CSA system). One of these also showed Glutl reactivity. Another tumor contained a few CD34-positive cells.
Conventional MPNST included in this study showed a cellular spindle cell proliferation alternating with hypocellular areas and sometimes were associated with neurofibroma-like areas, small cell areas, or whorl formation. S-100 protein-positive cells were seen in six of seven tumors (Fig. 7A). The number of positive cells varied greatly between tumors. EMA-positive cells were demonstrated in six of seven tumors by the CSA system, and Glut1, in two of six tumors by ENVISION+ (Fig. 7B). Cellular morphology of positive cells was varied, ranging from nondescript spindle cells to small round cells. Cells constituting whorls and perineurium-like structures also showed immunoreactivity to EMA/ Glut1. A few CD34-positive cells were observed in four of seven tumors (Fig. 7C).

In the perineurial MPNST characterized by welldeveloped cellular whorls (Fig. 8A), many EMApositive cells were detected by the CSA system, and some also showed Glutl positivity (Fig. 8B). All four tumors exhibited EMA or Glutl immunoreactivity. On the other hand, S-100 protein was negative, whereas one tumor contained many CD34-positive cells.

\section{DISCUSSION}

Among the immunohistochemical markers for nerve sheath cells, S-100 protein was introduced in immunohistochemistry very early and is still a useful marker for Schwann cells (15). Some studies have reported immunoreactivity of EMA in peri-
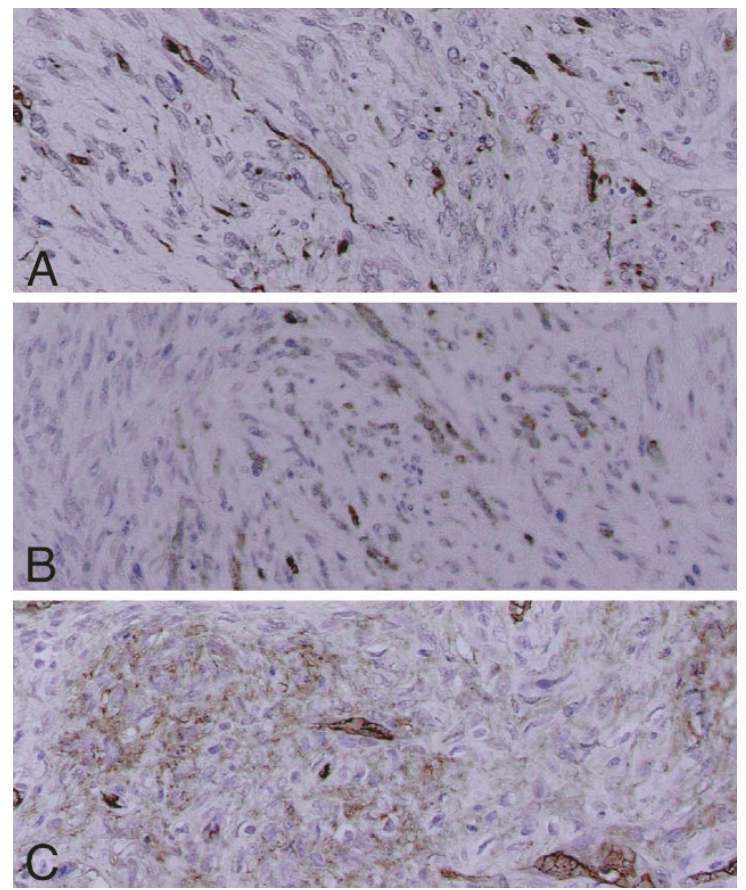

FIGURE 7. Conventional MPNST, composed of varied numbers of tumor cells positive for S-100 protein (A), Glut1 (B), and CD34 (C). 


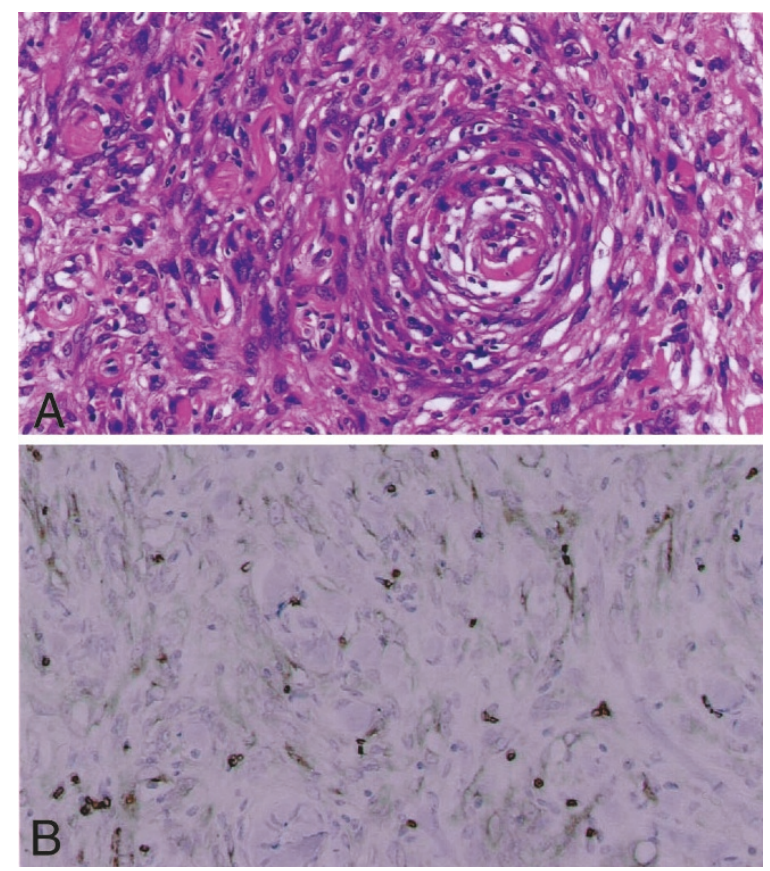

FIGURE 8. Perineurial MPNST. A, a characteristic whorl formation of spindle-shaped tumor cells. B, many tumor cells showing Glut1 immunoreactivity.

neurial cells and their tumors $(3,16,17)$. With the expression of this epithelial marker as well as the ultrastructural evidence, perineuriomas have recently been established as a distinctive peripheral nerve tumor entity $(6,11)$, and several variants, such as sclerosing $(12,18)$, reticular $(19)$, and intraneural (20) types have been described. In addition, a malignant counterpart of perineuriomas has been proposed, based on the characteristic microscopic features and EMA immunoreactivity (13). Furthermore, Glutl was recently added to the group of nerve sheath cell markers (4). Glutl is a transmembrane protein that mediates facilitative transport of glucose (21). Its expression has been reported in various normal and neoplastic conditions as well as in the erythrocyte membrane $(21,22)$. In normal peripheral nerves, Glutl is expressed by perineurial cells $(4,23)$. However, no immunohistochemical studies about this protein have been carried out on peripheral nerve sheath tumors, to our knowledge. Another marker of nerve sheath cells is CD34, which was first identified as a marker of hematopoietic progenitor cells. Soon, CD34 expression was identified in several soft tissue tumors, including dermatofibrosarcoma protuberans, solitary fibrous tumor, epithelioid sarcoma, gastrointestinal stromal tumor, and so on (11). Although CD34-positive cells have also been reported in some nerve lesions (10), the nature of the positive cells has not been clarified.

The present immunohistochemical studies on normal nerves and traumatic neuromas suggest that Glut1 is a useful marker for perineurial cells like EMA and that CD34 seems to be expressed by endoneurial fibroblasts. Glutl was solely localized on the perineurium of proliferated nerve fascicles in neuromas. CD34-positive cells were mainly present within the endoneurium and were not consistent with EMA/Glut1-positive perineurial cells or S-100 protein-positive Schwann cells, suggesting that the CD34-positive cells may correspond to endoneurial fibroblasts. Weiss and Nickoloff (10) also considered that CD34-positive cells were distinct from Schwann cells, "conventional" fibroblasts, and perineurial cells.

The present studies confirmed that schwannomas are principally composed of S-100 protein-immunoreactive Schwann cells (2). Their capsules consistently expressed EMA/Glut1-immunoreactivities (16), indicating that they are directly derived from the perineurium of original nerves. Furthermore, there were a few cells exhibiting both perineurial (Glut1) and fibroblastic (CD34) immunophenotypes at the peripheral areas close to the capsule. Some ultrastructural studies of neurofibromas indicated the presence of an intermediate type of cells, between perineurial cells and fibroblasts $(5,8)$. Our immunohistochemical results may also suggest the presence of intermediate cells. As reported by Weiss and Nickoloff (10), CD34positive fibroblastic cells were demonstrated in Antoni $\mathrm{B}$ areas and may contribute to the accumulation of myxoid substances in these areas.

The constituents of neurofibromas are still controversial (9). Ultrastructural studies suggested the presence of perineurial cells, endoneurial fibroblasts, and intermediate cells, as well as Schwann cells $(5,8)$. However, the heterogeneous cell populations have not been confirmed immunohistochemically $(9,16$, 17). Individual tumor cells dispersed in neurofibromas usually lack EMA immunoreactivity, although perineurium-like structures are positive. In the present study, we used a highly sensitive immunohistochemical procedure, the CSA system, to enhance EMA immunoreactivity. This method enables a trace of antigens to be detected. EMA immunoreactivity enhanced by the CSA system was demonstrated not only on perineurium-like structures but also on many individual tumor cells. Considering these results, neurofibromas contain a varied number of perineurial cells, but most of them could not be demonstrated by conventional immunohistochemical methods, probably because of the lower level of antigen expression and a sparse distribution of slender tumor cells (9). In addition, CD34 immunoreactivity suggests the presence of endoneurial fibroblasts in neurofibromas. Therefore, the heterogeneous cellular constituents of neurofibromas were immunohistochemically confirmed in the present study.

The cellular heterogeneity is also shown in conventional MPNST. In addition to S-100 protein- 
positive Schwann-like cells, there were varied numbers of EMA/Glut1-positive cells and CD34-positive cells, indicating the constitutional similarity to neurofibromas, as suggested elsewhere (24-26). About one third to one half of MPNST lack S-100 protein immunoreactivity $(6,11)$. The negative reaction may be caused by not only tumor cell anaplasia but also by different constituents than Schwann cells. For the immunohistochemical diagnosis of MPNST, nerve sheath markers other than S-100 protein, such as CD57 (Leu-7), EMA, Glut1, and CD34, should also be included in the panel of antibodies.

All tumors of perineuriomas and perineurial MPNST were S-100 protein negative and EMA and/or Glut1 positive. Interestingly, some tumors also included CD34-positive fibroblastic cells, suggesting the presence of transitional form.

In summary, the present study revealed that various lesions of the peripheral nerve show characteristic cellular compositions. Glutl as well as EMA are useful markers for perineurial cells. To demonstrate the latter properly, more sensitive immunohistochemical procedures appear to be necessary. CD34 may be expressed by endoneurial fibroblasts, which are another important constituent in some peripheral nerve lesions.

Acknowledgments: The authors thank Dr. S. Shinomiya, Department of Pathology, Naruto Hospital, Tokushima, Japan for kindly providing materials and thank Mr. T. Mochino, Department of Pathology, Saitama Medical School, for technical assistance.

\section{REFERENCES}

1. Ortiz-Hidalgo C, Weller RO. Peripheral nervous system. In: Sternberg SS, editor. Histology for pathologists. 2nd ed. Philadelphia, PA: Lippincott-Raven; 1997. p. 285-311.

2. Erlandson RA. Diagnostic transmission electron microscopy of tumors with clinicopathological, immunohistochemical, and cytogenetic correlations. New York: Raven Press; 1994.

3. Perentes E, Nakagawa Y, Ross GW, Stanton C, Rubinstein LJ. Expression of epithelial membrane antigen in perineurial cells and their derivatives. An immunohistochemical study with multiple markers. Acta Neuropathol (Berl) 1987;75:160-5.

4. Fogt F, Capodieci P, Loda M. Assessment of perineurial invasion by GLUT-1 immunohistochemistry. Appl Immunohistochem 1995;3:194-7.

5. Erlandson RA, Woodruff JM. Peripheral nerve sheath tumors: an electron microscopic study of 43 cases. Cancer 1982;49: 273-87.

6. Scheithauer BW, Woodruff JM, Erlandson RA. Tumors of the peripheral nervous system. Atlas of tumor pathology. 3rd series. Fascicle 24. Washington, D.C.: Armed Forces Institute of Pathology; 1999.

7. Giannini C, Scheithauer BW, Jenkins RB, Erlandson RA, Perry A, Borell TJ, et al. Soft-tissue perineurioma. Evidence for an abnormality of chromosome 22, criteria for diagnosis, and review of the literature. Am J Surg Pathol 1997;21:16473.

8. Hirose T, Sano T, Hizawa K. Ultrastructural localization of S-100 protein in neurofibromas. Acta Neuropathol (Berl) 1986;69:103-10.

9. Erlandson RA. The enigmatic perineurial cells and its participation in tumors and in tumorlike entities. Ultrastruct Pathol 1991;15:335-51.

10. Weiss SW, Nickoloff BJ. CD-34 is expressed by a distinctive cell population in peripheral nerve, nerve sheath tumors, and related lesions. Am J Surg Pathol 1993;17:1039-45.

11. Weiss SW, Goldblum JR. Enzinger and Weiss's soft tissue tumors. 4th ed. St. Louis: Mosby; 2001.

12. Hirose T, Scheithauer BW. "Sclerosing" perineurioma: a tumor variant? Int J Surg Pathol 1999;7:133-40.

13. Hirose T, Scheithauer BW, Sano T. Perineurial malignant peripheral nerve sheath tumor (MPNST). A clinicopathologic, immunohistochemical, and ultrastructural study of seven cases. Am J Surg Pathol 1998;22:1368-78.

14. Sanno N, Teramoto A, Sugiyama M, Itoh Y, Osamura RY. Application of catalyzed signal amplification in immunodetection of gonadotropin subunits in clinically nonfunctioning pituitary adenomas. Am J Clin Pathol 1996;106:16-21.

15. Nakajima T, Kameya T, Watanabe S, Hirota T, Sato Y, Shimosato Y. An immunoperoxidase study of S-100 protein distribution in normal and neoplastic tissues. Am J Surg Pathol 1982;6:715-27.

16. Theaker JM, Gatter KC, Puddle J. Epithelial membrane antigen expression by the perineurium of peripheral nerve and in peripheral nerve tumours. Histopathology 1988;13:171-9.

17. Ariza A, Bilbao JM, Rosai J. Immunohistochemical detection of epithelial membrane antigen in normal perineurial cells and perineurioma. Am J Surg Pathol 1988;12:678-83.

18. Fetsch J, Miettinen M. Sclerosing perineurioma. A clinicopathologic study of 19 cases of a distinctive soft tissue lesion with a predilection for the fingers and palms of young adults. Am J Surg Pathol 1997;21:1433-42.

19. Van Roggen JFG, McMenamin ME, Belchis DA, Nielsen GP, Rosenberg AE, Fletcher CDM. Reticular perineurioma. A distinctive variant of soft tissue perineurioma. Am J Surg Pathol 2001;25:485-93.

20. Emory TS, Scheithauer BW, Hirose T, Wood M, Onofrio BM, Jenkins RB. Intraneural perineurioma. A clonal neoplasm associated with abnormalities of chromosome 22. Am J Clin Pathol 1995;103:696-704.

21. Mueckler M. Facilitative glucose transporters. Eur J Biochem 1994;219:713-25.

22. Kalir T, Wang BY, Goldfischer M, Haber RS, Reder I, Demopoulos R, et al. Immunohistochemical staining of GLUT1 in benign, borderline, and malignant ovarian epithelia. Cancer 2002;94:1078-82.

23. Kakita Y, Oshiro K, O’Brian DS, Puri P. Selective demonstration of mural nerves in ganglionic and aganglionic colon by immunohistochemistry for glucose transporter-1. Prominent extrinsic nerve pattern staining in Hirshsprung disease. Arch Pathol Lab Med 2000;124:1314-9.

24. Herrera GA, de Moraes HP. Neurogenic sarcomas in patients with neurofibromatosis (von Recklinghausen's disease). Light, electron microscopy and immunohistochemical study. Virchows Arch (Pathol Anat) 1984;403:361-76.

25. Fisher C, Carter RL, Ramachandra S, Thomas DM. Peripheral nerve sheath differentiation in malignant soft tissue tumours: an ultrastructural and immunohistochemical study. Histopathology 1992;20:115-25.

26. Hirose T, Hasegawa T, Kudo E, Seki K, Sano T, Hizawa K. Malignant peripheral nerve sheath tumors: an immunohistochemical study in relation to ultrastructural features. Hum Pathol 1992;23:865-70. 